\title{
Relationship between Emotional Intelligence and Academic Achievement in Algebra of First Year Mathematics and Science Education Students at the Copper belt University in Zambia
}

\author{
Allan Musonda ${ }^{1^{*}}$, Overson Shumba ${ }^{1}$, Frank. P. Tailoka ${ }^{2}$ \\ ${ }^{I}$ The Copperbelt University, Department of Mathematics and Science Education, Kitwe, Zambia \\ ${ }^{2}$ The Copperbelt University, Department of Mathematics, Kitwe, Zambia
}

*Corresponding Author: Allan Musonda, The Copperbelt University, Department of Mathematics and Science Education, Kitwe, Zambia.

\begin{abstract}
The aim of this study was to investigate the relationship between emotional intelligence and academic achievement in algebra (mathematics) among first year students in the Department of Mathematics and Science Education (DMSE) at the Copperbelt University in Zambia. Two cohorts (2016/2017 and 2017/2018) students in the DMSE were purposively selected for the study. One hundred and seven (25 females, 82 males) students from the 2016/2017 cohort and 138 (47 females, 91 males) students from the 2017/2018 cohort completed three research instruments. The instruments were the Schutte Self-Report Emotional Intelligence Test (SSEIT), Grade 12 level Algebra Achievement Test, and First Year University Level Algebra Test. Data were analyzed using Spearman's correlation coefficient and Mann-Whitney U Test. The results revealed no significant relationship between emotional intelligence and academic achievement in algebra from both cohorts. Additionally, Mann-Whitney U Test results showed that there was no significant differences in emotional intelligence between the two cohorts. This study reveals that emotional intelligence could not significantly predict academic achievement in Algebra. The results of this study are in agreement with other studies conducted in other countries.
\end{abstract}

Keywords: emotional intelligence, academic achievement, algebra, mathematics and science education, first year students.

\section{INTRODUCTION}

Learning institutions are concerned with academic achievement of their learners. Teachers, lecturers and other stakeholders in the education system want to see learners succeed in their academic work. Academic achievement, thus, occupies an important place in the life of the students' education. Students who do well in school are better able to achieve occupational and economic success in their adult lives (Muhammed \& Kajuru, 2019). Academic achievement indicates the progress made by the learners. A number of factors affect academic achievement of students (Enu, Agyman, \& Nkum, 2015). Enu et al. (2015) outlined a number of factors, which affect academic achievement. The factors were categorized into three: students' factors, socio economic factors and school based factors. Muhammed and Kajuru (2019) also indicated factors that impact on academic achievement such as family income, adequacy of lecture halls, students' personality characteristics and interest in the course of study.

Academic achievement of students has usually been measured using tests or other forms of standardized examination (Tyavbee \& Abogunde, 2018). The measures used in this study to measure academic achievement are Grade 12 level algebra test and First year university level algebra test. Academic achievement is important for the successful development of young people in society. Students who do well in school are better able to make the transition into adulthood and to achieve occupational and economic success.

A number of researchers have studied the concept of emotional intelligence since its introduction in the research world in the early 1990s. Salovey and Mayer (1990) were the first researchers to conceptualize the construct of emotional intelligence. They defined emotional intelligence as "the ability to monitor one's own and others' emotions, to discriminate among them and to use the 
information to guide one's thinking and actions" (p. 189). Goleman (1995) showed interest in the concept of emotional intelligence and studied it and its implications to an individual. Goleman defined emotional intelligence as a set of abilities that enable an individual to motivate himself/herself, persist in the face of frustrations, to control impulse and delay gratification. It also includes the ability to regulate one's moods and keep distress from overwhelming an individual's ability to think, to empathize, and to hope. Goleman argued that emotional intelligence was what made a difference between successful people and unsuccessful people in life. The belief by Goleman was that individuals who score highly on emotional intelligence are likely to be successful in other areas of life. Goleman (1998) claimed that emotional intelligence could be more important than IQ in predicting success in life for individuals. Goleman proposed five domains of emotional intelligence. One of the domains is motivation. Motivation involves the ability of an individual to overcome obstacles in order to achieve success. Thus, it is an important component needed in academic work. In this way, emotional intelligence is related to academic achievement. In fact, Goleman argued that IQ can predict only 20 percent of academic achievement and the rest can be predicted by emotional and social intelligence. Individuals scoring higher on emotional intelligence can also demonstrate higher commitment. Therefore, this study was set out on the same premise as Goleman and other researchers that there was a positive relationship between academic achievement in algebra and emotional intelligence of first year mathematics and science education students at CBU.

Following their continued research on the concept, Mayer and Salovey (1997) revised their initial definition of emotional intelligence to the ability to perceive emotion, integrate emotion in order to facilitate thought, understand emotions and to regulate emotions to promote personal growth. They proposed a model of emotional intelligence, which presented four branches, namely: i) Perception of emotion, ii) Emotional facilitation, iii) Understanding of emotions, and iv) Management of emotions.

Bar-On (1997) defined emotional intelligence as the ability to understand oneself and others, to relate well to people, and being able to adapt to immediate surroundings. Bar-On asserts that emotional intelligence develops over time and that it can be improved through training. He postulates that those individuals with higher than average EQs are in general more successful in meeting environmental demands and pressures. He also notes that a deficiency in emotional intelligence can mean a lack of success and the existence of emotional problems. Bar-On advocates a mixed model of emotional intelligence where he regards emotional intelligence and cognitive intelligence as constructs contributing equally to a person's general intelligence, which then offers an indication of one's potential to succeed in life.

Schutte et al. (1998) based their definition of emotional intelligence on the definition of Mayer and Salovey. However, Schutte et al. argued that emotional intelligence should be measured as a whole and not in terms of components. They referred to this as global emotional intelligence or simply total emotional intelligence. According to Schutte et al. (1998) emotional intelligence can be classified into three domains: i) Perceiving emotions - the ability to identify one's own emotions and those of others ii) Using emotions - the ability to harness emotions in order to carry out different cognitive activities, such as thinking and problem solving. iii) Understanding emotions - the ability to comprehend and appreciate intricate relationships among emotions. iv) Managing emotions - the ability to regulate emotions in both ourselves and in others.

\subsection{Emotional Intelligence and Academic Achievement}

The relationship between emotional intelligence and academic achievement has been extensively studied since the 1990s. A number of studies have revealed that emotional intelligence is positively correlated to students' academic achievement (Banat \& Rimawi, 2014;Kolachina, 2014;Ramesh, Thavaraj, \& Ramkumar, 2016).Additionally, researchers believe that higher levels of emotional intelligence predict academic achievement (Ali \& Ali, 2016; Banat \& Rimawi, 2014; Joshi et al., 2012; Mohzan et al., 2013). They assert that students with higher levels of emotional intelligence, apart from performing highly, do display positive behaviours such as self-discipline, motivation, and good organization in their work (Duckworth \& Seligman, 2005). A study by Parker et al. (2004) also revealed that students who were highly successful in their academic work displayed higher levels of emotional intelligence than those who struggled academically. 
Although a number of studies have revealed positive correlation between emotional intelligence and academic achievement, other studies have shown different results. In particular, some studies have shown that there is no statistically significant correlation between emotional intelligence and academic achievement of students (e.g. Alghamdi, 2014;Devi \& Narayanamma, 2014; Kashani et al., 2012; Tolu \& Adedayo, 2015). The studies indicate that underachievement of students cannot be attributed to their levels of emotional intelligence. Other factors could be the reason for such underachievement.

Generally, literature has shown that high emotional intelligence is a predictor of academic achievement among learners in different institutions of learning. Nevertheless, the present study is necessary for two among other reasons: i) few studies have focused on the relationship between emotional intelligence and academic achievement in mathematics (algebra) ii) participants in these studies are different culturally from students in Zambian universities. Furthermore, studies on emotional intelligence and its relationship with academic achievement are scanty, if any, in the Zambian context. Therefore, this study contributes to literature on emotional intelligence and academic achievement in Zambia.

\subsection{Statement of the Problem}

Underachievement in first year mathematics (MA 120) among students in the Department of Mathematics and Science Education at CBU has been a challenge. Students' achievement has been a struggle over the years. For instance, the Examiners' Reports for four consecutive years $(2012,2013$, 2014 and 2015) showed that 43\%, 47\%, 39\% and 34\% respectively of first year students in the Department of Mathematics and Science Education at CBU failed MA 120. The argument is that these students were admitted to the University based on their good grades (a merit or better) in secondary school mathematics and other subjects. As such, their underachievement could be attributed to some factors: social, educational, psychological, and personal factors. Researchers have shown that emotional intelligence is a construct, which is associated with positive academic achievement (Goleman, 1995; Salovey \& Mayer, 1990; Schutte et al., 1998). With this in mind, the current study was conducted to establish whether there was a relationship between students' emotional intelligence and academic achievement in mathematics (algebra). Should a positive relationship be found, then training of first year students in emotional intelligence could be recommended. Underachievement of students in mathematics at first year is of concern in that it affects the individual students, their families, the University, and the country in various ways. For instance, students may delay in completing their programmes, or may not even complete as they may end up failing other courses as well in the process. This is a drain to the country's and the university's resources. This study, therefore was aimed at investigating the relationship between emotional intelligence of first year students in the DMSE and their academic achievement in mathematics (algebra) at CBU in Zambia and recommend for students' training in emotional intelligence should it be found that there is a positive correlation between the two variables.

\subsection{Purpose of the Study}

The purpose of the study was to examine the relationship between emotional intelligence of first year students in the DMSE and their academic achievement in mathematics (algebra) at CBU in Zambia. The researcher aimed to recommend for first year students' training in emotional intelligence if it was found that there was a positive correlation between students' emotional intelligence and their achievement in mathematics (algebra).

\subsection{Research Questions}

Arising from the purpose of the study, the following research questions were considered:

1. What is the relationship between students' emotional intelligence scores and their achievement on the Grade 12 Level Algebra Achievement Test?

2. What is the relationship between students' emotional intelligence scores and their achievement on the First Year University Level Algebra Achievement Test?

3. Is there any significant difference in emotional intelligence between the two cohorts? 


\section{METHOD}

\subsection{Research Design}

This study adopted a correlational descriptive survey research design. The purpose of the study was to determine whether there was any relationship between first year students' emotional intelligence and their academic achievement in mathematics (algebra). The students were enrolled in a mathematics and science teacher programme in the Department of Mathematics and Science Education at the Copperbelt University in Zambia.

\subsection{Sample}

A sample of 107 ( 25 females, 82 males) from the 2016/2017 cohort and 138 (47 females, 91 males) students from the 2017/2018 cohort at CBU were purposively selected to participate in the study. The students were all first years in the Department of Mathematics and Science Education at CBU. They were deliberately targeted for the study because they possessed the characteristics of students training to be secondary school teachers. The mean age of the participants in the 2016/2017 cohort was 20.53 years; while the mean age of the participants in the 2017/2018 cohort was 20.72 years.

\subsection{Measures}

Schutte Self-Report Emotional Intelligence Test was used to measure students' emotional intelligence. The SSEIT is a 33-item, self-report questionnaire developed by Schutte et al. (1998) to measure total emotional intelligence. The items on the questionnaire are scored on a 5 point Likert scale (1-Strongly disagree; 2-Disagree; 3-Neither disagree nor agree; 4-Agree; 5-Strongly Agree). The minimum total score is 33 while the maximum score is 165 .

Two researcher designed algebra tests were used to measure students' academic achievement in algebra. The two tests were a Grade 12 level Algebra Achievement Test developed to assess students' conceptual knowledge in algebra at Grade 12 level. The other tests was a First Year University Level Algebra achievement Test developed to assess students' knowledge in algebra at first year university level.

\subsection{Reliability of Instruments}

Developers of the instrument (SSEIT) and other researchers (Austin, Saklofske, Huang, \& McKenney, 2004; Brown \& Schutte, 2006; Schutte et al., 1998; Thingujam \& Ram, 2000) have established its reliability. However, those studies are from different settings. Thus, it was necessary that reliability of the SSEIT in the Zambian setting be established. The reliability was calculated using Cronbach's reliability test and Cronbach's alpha obtained was above 0.7, for both cohorts. This revealed acceptable reliability levels (Pallant, 2007).

Algebra tests' reliability were calculated using a strategy called Parallel forms of reliability. The correlation coefficient of 0.889 (or 0.9) for the Grade 12 level Algebra Test and coefficient correlation of 0.859 (or 0.9 ) for first year university level algebra showed good reliability of both instruments.

\subsection{Procedure}

The three instruments were administered to the participants in two segments of time. The first administration was in December 2016. The second phase was in April 2018. Participants completed all the three instruments in the presence of the researcher and a departmental colleague who was assisting in the process. All the participants participated in the study voluntarily and were free to withdraw their participation at any time they so wished. The purpose of the study was explained to the participants. Additionally issues of confidentiality and anonymity were guaranteed.

\subsection{Data Analysis}

In determining which statistical analysis to use, normality tests were conducted on the three data sets: emotional intelligence scores, Grade 12 level algebra scores, and first year university level algebra scores. Normality test results for both cohorts indicated that the three data sets (apart from the 2017/2018 SSEIT scores) were not normally distributed. Thus, data was analyzed by performing Spearman's correlations and Mann-Whitney U test. Spearman's correlations were used to determine the relationship between emotional intelligence and academic achievement in algebra (Grade 12 level algebra and first year university level algebra). Mann-Whitney $U$ test was used to find out if there were any significant differences in emotional intelligence between the two cohorts. 
Relationship between Emotional Intelligence and Academic Achievement in Algebra of First Year Mathematics and Science Education Students at the Copper belt University in Zambia

\section{ReSUlts}

The first question of the study was analyzed by performing Spearman's correlation. Results revealed a negative, weak and not statistically significant correlation $\left[r_{s}(107)=-.184, p=.058>.05\right.$, two-tailed] between students' emotional intelligence and achievement in the Grade 12 Level Algebra Achievement Test in the 2016/2017 cohort. Additionally, the coefficient of determination $\mathrm{R}^{2}[-.184 \mathrm{x}$ (-.184)] indicated that approximately $3 \%$ of the variance in Grade 12 Level Algebra Achievement Test scores could be predicted from SSEIT scores. Results for the 2017/2018 cohort, also revealed a negative, weak and not statistically significant correlation $\left[r_{s}(138)=-.005, p=.953>.05\right.$, two-tailed $]$ between students' emotional intelligence and their achievement on the Grade 12 Level Algebra Achievement Test. The coefficient of determination $\mathrm{R}^{2}[-.005 \times(-.005)]$ indicated that approximately $0.0025 \%$ of the variance in Grade 12 Level Algebra Achievement Test scores could be predicted from SSEIT scores. Results of Spearman's correlation coefficients for both cohorts are presented in Table 1.

Table1. Spearman's Correlations: Grade 12 Level Algebra and Emotional Intelligence in the Two Cohort

\begin{tabular}{|l|l|l|l|l|l|}
\hline & & $\begin{array}{l}2016 / 2017 \\
\text { Grade12 level } \\
\text { algebra test }\end{array}$ & SSEIT & $\begin{array}{l}\text { 2017/2018 } \\
\text { Grade12 level algebra } \\
\text { test }\end{array}$ & SSEIT \\
\hline $\begin{array}{l}\text { Grade12 level } \\
\text { algebra test }\end{array}$ & $\begin{array}{l}\text { Correlation } \\
\text { Coefficient Sig. } \\
(2-\text { tailed })\end{array}$ & 1.000 & $\begin{array}{c}-.184 \\
.058\end{array}$ & 1.000 & -.005 \\
& $\mathrm{~N}$ & 107 & 107 & 138 & .953 \\
& $\begin{array}{l}\text { Correlation } \\
\text { Coefficient Sig. } \\
\text { SSEIT }\end{array}$ & -.184 & 1.000 & -.005 & .953 \\
& $\mathrm{~N}$ & 1058 & 107 & 138 & 1.000 \\
& & & & 138 \\
\hline
\end{tabular}

*Correlation is significant at the 0.05 level (2-tailed)

The correlation results in both cohorts provided evidence that there was effectively no correlation between the two variables. As such, there was no significant relationship between emotional intelligence and achievement in Grade 12 level algebra test.

The second research question sought to determine whether there was any relationship between students' emotional intelligence scores and their achievement on the First Year University Level Algebra Achievement Test. Spearman's correlation was used to answer the question. Spearman's Rank Order Correlation (rho) results revealed that there were weak, negative, and not statistically significant correlation between students' emotional intelligence scores and achievement in university algebra in both the $2016 / 2017$ cohort $\left[r_{s}(107)=-.075 ; p=.441>.05\right]$ and the 2017/2018 cohort $\left[r_{s}(138)=-.091 ; p=.289>.05\right]$. The results provided evidence that there was no statistically significant relationship between the students' emotional intelligence and achievement in university first year level algebra for both cohorts. The coefficient of determination $\mathrm{R}^{2}[-.075 \times(-.075)]$ indicated that approximately $0.6 \%$ of the variance in First Year University Level Algebra Achievement Test scores in the 2016/2017 cohort could be explained by the students' emotional intelligence. In the $2017 / 2018$ cohort, the coefficient of determination $\mathrm{R}^{2}[-.091 \times(-.091)]$ indicated that approximately $0.8 \%$ of the variance in First Year University Level Algebra Achievement Test scores could be explained by the students' emotional intelligence. Table 2. Shows SPSS correlation results for the 2016/2017 and 2017/2018 cohorts.

Table2. Spearman's Correlations: First Year University Level Algebra and Emotional Intelligence

\begin{tabular}{|c|c|c|c|c|c|}
\hline & & $\begin{array}{l}2016 / 2017 \\
\text { First year } \\
\text { university level } \\
\text { algebra test }\end{array}$ & SSEIT & $\begin{array}{l}\text { 2017/2018 } \\
\text { First year } \\
\text { university level } \\
\text { algebra test }\end{array}$ & SSEIT \\
\hline $\begin{array}{l}\text { First year } \\
\text { university } \\
\text { level algebra } \\
\text { test }\end{array}$ & $\begin{array}{l}\text { Correlation } \\
\text { Coefficient Sig. } \\
(2-\text { tailed }) \\
\mathrm{N}\end{array}$ & $\begin{array}{l}1.000 \\
107\end{array}$ & $\begin{array}{l}-.075 \\
.441 \\
107\end{array}$ & $\begin{array}{l}1.000 \\
138\end{array}$ & $\begin{array}{r}-.091 \\
.289 \\
138\end{array}$ \\
\hline SSEIT & $\begin{array}{l}\text { Correlation } \\
\text { Coefficient Sig. } \\
\text { (2-tailed) } \\
\mathrm{N}\end{array}$ & $\begin{array}{l}-.075 \\
.441 \\
107\end{array}$ & $\begin{array}{l}1.000 \\
107\end{array}$ & $\begin{array}{l}-.091 \\
.289 \\
138\end{array}$ & $\begin{array}{l}1.000 \\
138 \\
\end{array}$ \\
\hline
\end{tabular}

*Correlation is significant at the .05 level (2-tailed) 
The correlation result provided evidence that there was no statistically significant relationship between the students' emotional intelligence and achievement in first year university level algebra.

Results for both cohorts have revealed that there is no statistically significant correlation between emotional intelligence and achievement in algebra.

The third research question sought to find out whether there were any differences in emotional intelligence between the two cohorts. Mann-Whitney U test was conducted, since the data was not normally distributed. The results revealed that there were no significant differences between the cohorts $(p=.940>.05)$. The median scores for 2016/2017 (130) and for 2017/2018 (130) also confirmed that the levels of emotional intelligence for the cohorts were the same. The mean scores were 129.17 and 129.88 for 2016/2017 and 2017/2018 cohorts respectively, further confirming that the two data sets reflected similarity in the level of the students' emotional intelligence.

\section{Discussion AND CONCLUSIONS}

The purpose of this study was to investigate the relationship between first year students' emotional intelligence and their academic achievement in algebra. The participants were first year students in the Department of Mathematics and Science Education at the Copperbelt University drawn from two academic cohorts: 2016/2017 and 2017/2018. Findings of the present study indicate that there is no positive statistically significant relationship between students' emotional intelligence and academic achievement in algebra. These findings contradict earlier studies (Ali \& Ali, 2016; Banat \& Rimawi, 2014; Joshi, Srivastava, \& Raychaudhuri, 2012; Mohzan, Hassan, \& Halil, 2013)which established that emotional intelligence is positively correlated with academic achievement. The findings in these studies have been significant. For instance, Banat and Rimawi (2014) conducted their study at the AlQuds University, Jerusalem, Abu Dies with the purpose of identifying the impact of emotional intelligence on academic achievement among students. The level of emotional intelligence for the students in this study was high and positively correlated with students' academic achievement. The study concluded that emotional intelligence was a predictor of students' academic achievement.

In contrast to studies that revealed a positive significant relationship between emotional intelligence and academic achievement, the present study is consistent with studies that did not find a positive, significant relationship between the two variables (e.g. Alghamdi, 2014; Devi \& Narayanamma, 2014; Kashani, Azimi, \& Sh, 2012; Tolu \& Adedayo, 2015). These studies did not reveal positive significant relationships between students' emotional intelligence and academic achievement.

The findings of this study contrast with the researcher's expectations. The researcher had hypothesized that there was a positive significant relationship between students' emotional intelligence and their academic achievement in algebra among first year mathematics and science education students at CBU. The results of the study suggest that students' underachievement in mathematics (algebra) at the Copperbelt University is due to other factors. From the percentage variance in both cohorts, it is clear that emotional intelligence does not predict academic achievement in algebra among first year mathematics and science education students at CBU. Although the results of this study do not fit with the theory that students with high levels of emotional intelligence are likely to perform better in their academic work than those with lower level of emotional intelligence, the results provide evidence to be careful in the way results are generalized.

The results of this study have their own limitations. Firstly, the results apply to first year students from one department in the University. As such, the results may not be generalized to the whole university and to every course. Furthermore, the results may not be generalized to all universities in Zambia. Therefore, further research is needed to establish whether the results of this study apply to other courses within the university and other universities in Zambia. Additionally, the data in this study was collected using an instrument (SSEIT) developed in a different setting from that of Zambia, as such there is a possibility of a slight difference in the findings if the data may be collected through an instrument developed for the Zambian setting. For instance, an instrument taking into consideration the cultural aspect of Zambian students can be designed and administered. The study considers only a small part of first year mathematics. Therefore, future studies may consider the complete first year mathematics course by compiling test results from all the three terms in an academic year. In this way, there would be more representation of the topics. Results from such studies can be examined to check whether they are consistent with the results of the present study.

The study reveals that there is no statistically significant correlation between emotional intelligence and achievement in algebra. It is suggested that emotional intelligence of students in a Zambian context has no relationship with academic achievement in algebra. Since the respondents in Schutte et 
al.'s (1998) study are culturally different from the respondents in this study, it could be argued that the SSEIT is a culturally specific instrument and may not transfer to other contexts e.g. the Zambian context.

Based on the findings in this study it can be concluded that first year students in the Department of Mathematics and Science Education at the Copperbelt University in Zambia have high emotional intelligence. However, there is no positive significant relationship between the students' emotional intelligence and their academic achievement in algebra. Both cohorts in the study revealed weak, negative and non-significant correlations. It can also be concluded that students from both cohorts have similar levels of emotional intelligence. In the first cohort $71 \%$ of the participants were above the average emotional intelligence score of 124 , while $70 \%$ in the second cohort scored above the average. This suggests that there is no difference in students' levels of emotional intelligence between the two cohorts.

\section{REFERENCES}

[1] Alghamdi, F. S. (2014). The role of trait emotional intelligence in individual performance: A descriptive study in Albaha University, Saudi Arabia. Journal of Service and Management, 7, 361 - 367. Retrieved from: http://dx.doi.org/10.4236/jssm.2014.75033.

[2] Ali, K., \& Ali, M. (2016). The relationship between emotional intelligence and academic achievements in males and females in Egyptian context. Psychology Research, 6(10), 567 - 578.

[3] Austin, E. J., Saklofske, D. H., Huang Sandra, H. S., \& McKenney, D. (2004). Measurement of trait emotional intelligence: testing and cross-validating a modified version of Schutte, et al.'s (1998) measure. Personality and Individual Differences, 36(3), 555-562.

[4] Banat, B. Y. I \& Rimawi, O. T. (2014). The impact of emotional intelligence on academic achievement: a case study of Al- Quds University students, International Humanities Studies, 1(2).

[5] Bar-On, R. (1997). Bar On Emotional Quotient Inventory: A measure of emotional intelligence. Toronto, Canada: Multi-Health Systems.

[6] Brown, R., \& Schutte, N. (2006). Direct and indirect relationships between emotional intelligence and subjective fatigue in university students. Journal of Psychosomatic Research, 60, 585-593.

[7] Devi, R. V \& Narayanamma, L. P. (2014). Academic achievement in Engineering: Does emotional intelligence matter? International Business Management Journal, 8(2), 85-92.

[8] Duckworth, A. L., \& Seligman, M. E. P. (2005). Self-discipline outdoes IQ in predicting academic performance of adolescents. Psychological Science, 16(12), 939-944.

[9] Enu, J., Agyman, O. K., \& Nkum, D. (2015). Factors influencing students' mathematics performance in some selected Colleges of Education in Ghana. International Journal of Education Learning and Development, 3(3), 68-74.

[10] Goleman, D. (1995). Emotional intelligence. New York: Bantam Books.

[11] Goleman, D. (1998). Working with emotional intelligence. New York: Bantam.

[12] Joshi, S. V., Srivastava, K., \& Raychaudhuri, A. (2012). A descriptive study of emotional intelligence and academic performance of MBBS students. Procedia-Social and Behavioral Sciences, 69(1), 2061-2067.

[13] Kashani, L. F., Azimi, L. A., \& Sh, V. (2012). Relationship between emotional intelligence and educational achievement. Procedia - Social and Behavioral Sciences, 1270 - 1275.

[14] Kolachina, A. (2014). Impact of emotional intelligence on academic achievements of expatriate college students in Dubai. International Journal of Social Science and Humanities Research 2(2), 97-103.

[15] Mayer, J. D., \& Salovey, P. (1997). What is emotional intelligence? In P. Salovey \& D. J. Sluyter (Eds.), Emotional development and emotional intelligence: Educational implications, (pp. 3-31). New York: Basic Books.

[16] Mohzan, M. A., Hassan, N., \& Halil, N. A. (2013). The Influence of emotional intelligence on academic achievement. Procedia - Social and Behavioral Sciences, 90(10), 303 -312.

[17] Muhammed, M. M \& Kajuru, J. Y (2019). Statistical analysis of the factors affecting students' academic performance in tertiary institutions: A case study of the department of statistics, Ahmadu Bello University, Zaria. International Journal of Statistics and Applied Mathematics 2019; 4(1): 58-61.

[18] Pallant, J. (2007). SPSS Survival Manual-A step by step guide to data analysis using SPSS for Windows (3rd ed.). Maidenhead: Open University Press. 
[19] Parker, J. D. A., Summerfeldt, L. J., Hogan, M. J., \& Majeski, S. A. (2004). Emotional intelligence and academic success: Examining the transition from high school to university. Personality and Individual Differences, 36, 163-173.

[20] Ramesh, S., Thavaraj, H. S., \& Ramkumar, D. (2016) Impact of emotional intelligence on academic achievements of college students - A review. International Journal of Business Management and Research, 6(2), 25-30.

[21] Salovey, P., \& Mayer, J. D. (1990). Emotional intelligence. Imagina-tion, Cognition, and Personality, 9 , $185---211$

[22] Schutte, N. S., Malouff, J. M., Hall, L. E., Haggerty, D. J., Cooper, J. T., Golden, C. J., \& Domheim, L. (1998). Development and validation of a measure of emotional intelligence. Personality and Individual Differences, 25, 167-177.

[23] Tolu, E. O., \& Adedayo, A. (2015) Emotional intelligence, academic procrastination and academic achievement in two tertiary institutions in South-Western Nigeria. Gender and Behaviour Journal, 13(1).

[24] Thingujam, N., \& Ram, U. (2000). Emotional intelligence scale: Indian norms. Journal of Education and psychology, 58, 40-45.

[25] Tyavbee, A. J. \& Abogunde. I. S (2018). Emotional intelligence and achievement of students in mathematics: A case study. Available from: https://www.researchgate.net/publication/333488663

\section{AUTHORS' BIOGRAPHY}

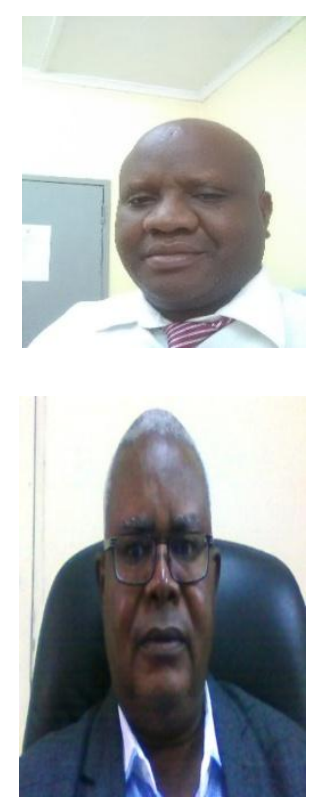

Allan Musonda, is a lecturer in Mathematics Education at the Copperbelt University in Zambia. He holds a Master of Education in Mathematics Education and a Bachelor of Science with Education (Mathematics major) from the University of Zambia. His research interests include emotional intelligence and mathematics teaching and learning, the place of Algebra in mathematics, learner centred teaching, and mentorship of secondary school mathematics teachers. This research article is the third based on his $\mathrm{PhD}$ thesis.

Dr. Overson SHUMBA, is a professor of science education in the School of Mathematics and Natural Sciences and directs the Centre for Academic Development at the Copperbelt University. He has more than 30 years of experience in higher education. He pursues research interests in mathematics and science teacher education, curriculum and instruction, and mainstreaming education for sustainable development.

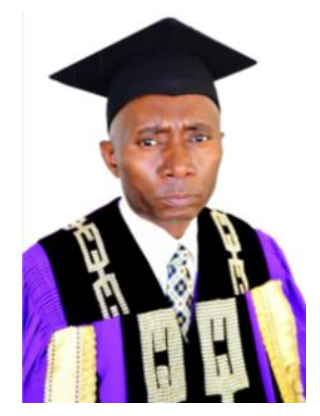

Tailoka Frank Patson, is a Lecturer in the School of Mathematics and Natural Sciences at the Copperbelt University. He holds a $\mathrm{PhD}$ in Statistics and Operations Research from Essex University, Mastersdegree in Mathematics from Washington State University, USA, a Bachelor's degree in Mathematics from the University of Zambia. His research interest include model selection, statistical modeling, Data Analysis, Biostatistics, Financial Mathematics and Optimisation, currently he is seconded to Mukuba University as a Director.

Citation: Allan Musonda, et.al. "Relationship between Emotional Intelligence and Academic Achievement in Algebra of First Year Mathematics and Science Education Students at the Copper belt University in Zambia" International Journal of Humanities Social Sciences and Education (IJHSSE), vol 8, no. 2, 2021, pp. 7-14. doi: https://doi.org/10.20431/2349-0381.0802002.

Copyright: (C) 2021 Authors. This is an open-access article distributed under the terms of the Creative Commons Attribution License, which permits unrestricted use, distribution, and reproduction in any medium, provided the original author and source are credited. 